\title{
1 Cellulose nanofibrils as templates for the design of
}

\section{$2 \operatorname{poly}\left({ }_{L}\right.$-lactide)-nucleating surfaces}

3

4 Shuji Fujisawa, Jiaqi Zhang, Tsuguyuki Saito, Tadahisa Iwata and Akira Isogai*

5

6

7

8

9

10

11

Graduate School of Agricultural and Life Sciences, The University of Tokyo, 1-1-1 Yayoi,

Bunkyo-ku, Tokyo 113-8657, Japan

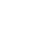

\footnotetext{
* Corresponding author. Tel: +8135841 5538; Fax : +81 358415269.

E-mail address: aisogai@mail.ecc.u-tokyo.ac.jp (A. Isogai).
}

\section{Abstract}

The abilities of surface-grafted cellulose nanofibrils for the nucleation of poly(L-lactide)

(PLLA) were investigated. Cellulose nanofibrils with a width of $\sim 3 \mathrm{~nm}$ were obtained from

wood cellulose via the oxidation using 2,2,6,6-tetramethylpiperidiniyl-1-oxyl as a catalyst and successive mechanical treatment. The cellulose nanofibril surfaces were selectively modified with amine-terminated poly(ethylene glycol) chains, via simple ionic bonds. The PEG-grafted cellulose nanofibril/PLLA composite films were prepared using a solvent casting method with chloroform. The isothermal and non-isothermal crystallization kinetics of the PLLA in the composites were studied using differential scanning calorimetry and polarized optical microscopy. The PEG chains were densely immobilized on the surface of the cellulose 
nanofibril templates, which had extraordinarily large specific surface areas. As a result, the surface-PEG layers effectively increased the rate of crystallization of the PLLA in the composites. Because of the increased degree of crystallinity after the isothermal crystallization, the composites showed better heat resistance than neat PLLA.

Keywords: Cellulose nanofibril; Polymer nanocomposite; Crystallization

\section{Introduction}

Poly $(\mathrm{L}$-lactide) (PLLA) is one of the most widely used biodegradable polymers. Because of its biocompatibility and renewability, PLLA is attractive for wide range of applications, including packaging [1-3], and medical [4-6] applications. However, a major drawback of PLLA is its low heat resistance. Although the crystallization of PLLA itself is a simple and effective way to solve the problem, the crystallization rate of PLLA is very low. Therefore, the use of neat PLLA typically results in an amorphous or very low-crystallinity material; the resultant material is easily distorted at its glass transition temperature $\left(T_{\mathrm{g}}\right)$ of $\sim 60^{\circ} \mathrm{C}$, which limits its potential for applications.

Much effort has been dedicated to enhancing the crystallization of PLLA. The addition of nucleating agents is an effective method for increasing the crystallization rate of PLLA. Some micro- or nano-elements such as talc [7-9], montmorillonite or nanosilica [10-14], carbon nanotubes [15-17], and graphene [18-20] are known to act as nucleating agents for the crystallization of PLLA. These nucleating agents have large specific surface areas, which is 
one of the key factors efficiently inducing the crystallization of PLLA on the surfaces.

Organic compounds such as benzenetricarboxylamide derivatives [21] and polysaccharide derivatives [22] have recently been shown to play an effective role as nucleating agents for PLLA. In addition to these nucleating agents, plasticizers such as poly(ethylene glycol) (PEG) can also enhance the crystallization [23-25]. PEG chains increase the polymer chain mobility, which leads to an increase in the crystallization of PLLA via a reduction in the energy required for the chain folding process during crystallization $[26,27]$.

Cellulose nanofibrils are promising candidates for nucleating agents of PLLA from renewable resources, and originate from naturally occurring cellulose microfibrils [28], which have high aspect ratios (>300) with small widths of 2-20 nm and high crystal moduli (130$150 \mathrm{GPa}$ [29-31]. It has been reported that these nanofibrils act as effective nucleating agents when they are incorporated in semi-crystalline polymers such as PLLA [32-34], polypropylene [35-38], and poly(3-hydroxybutyrate-co-3-hydroxyvalerate) [39]. Since the crystallization is initiated on their surfaces, the dispersibility of the nanofibrils in polymer matrices significantly affects the nucleation rate $[32,33]$. However, it is typically difficult to disperse hydrophilic cellulose nanofibrils in a hydrophobic polymer matrix without any agglomeration.

In our previous study, we showed a method that was used to achieve the individual dispersion of cellulose nanofibrils in a hydrophobic PLLA matrix via the surface modification of 2,2,6,6-tetramethylpiperidiniyl-1-oxyl (TEMPO)-oxidized cellulose nanofibrils (TOCNs) [40]. Carboxyl groups are exposed in high densities on the surface of TOCNs [41,42], and 
these groups can be used as selective anchoring sites for many kinds of functional groups [4350]. When long PEG chains are grafted onto the carboxyl groups, the PEG-grafted TOCNs (PEG-TOCNs) can be dispersed at the individual nanofibril level in a PLLA matrix, and the resultant PEG-TOCN/PLLA composites show enhanced mechanical properties with only small amounts of the PEG-TOCNs added.

In this study, we studied the nucleating abilities of the PEG-TOCNs for the crystallization of PLLA. TOCNs were prepared from wood cellulose, and the surface carboxyl groups were selectively modified with PEG chains via simple ionic bonds. Two PEGs with different chain lengths were used as grafting agents to evaluate the effects on the nucleating properties. PEGTOCN/PLLA composites containing 0.5 and $1.0 \mathrm{wt} \%$ of TOCNs were prepared by casting and drying mixtures of the PEG-TOCN dispersions and the PLLA solutions in chloroform. The crystallization behavior of the PEG-TOCN/PLLA composites was investigated under isothermal and non-isothermal conditions.

\section{Materials and methods}

\subsection{Materials}

A never-dried softwood bleached kraft pulp (Nippon Paper Ind., Japan), which contained approximately $90 \%$ cellulose and $10 \%$ hemicelluloses, was used as the original wood cellulose. Two amine-terminated PEGs, PEG(23)- $\mathrm{NH}_{2}$ and PEG(48)- $\mathrm{NH}_{2}$ (Sunbright MEPA$10 \mathrm{H}$ and MEPA-20H with $\mathrm{n}=23$ and $\mathrm{n}=48$, respectively) were obtained from NOF Corp. (Japan). PLLA with $M_{\mathrm{w}}=94,000$ and $M_{\mathrm{n}} 45,000 \mathrm{~g} \mathrm{~mol}^{-1}$ (Lacty ${ }^{\circledR}$ ) was supplied from Toyota 
Motor Corp., Japan. All other reagents were purchased from Wako Pure Chemicals, Co. Ltd., Japan, and used as received.

\subsection{Preparation of PEG-TOCN dispersion in chloroform}

TEMPO-oxidized cellulose was obtained according to a previously reported method [40], using the TEMPO/NaBr/NaClO system with $3.8 \mathrm{mmol}$ sodium hypochlorite per gram of cellulose. Oxidation was subsequently carried out with sodium chlorite at $\mathrm{pH} 4.8$, to convert the aldehyde groups still remaining after the TEMPO-mediated oxidation to carboxyls. The TEMPO-oxidized cellulose thus obtained had a carboxylate content of $1.30 \mathrm{mmol} \mathrm{g}^{-1}$, which was determined using conductivity titration. Based on this carboxylate content, the average density of the carboxyl groups on the surface of TOCNs was calculated to be 1.4 groups $\mathrm{nm}^{-2}$ [40], which was calculated from the width $(\sim 3 \mathrm{~nm})$ and carboxylate content $\left(1.3 \mathrm{mmol} \mathrm{g}^{-1}\right)$ of the TOCNs based on the cellulose microfibril model [42]. The TEMPO-oxidized cellulose was then suspended in water at a concentration of $0.1 \mathrm{w} / \mathrm{v} \%$ consistency. This suspension was homogenized at $7500 \mathrm{rpm}$ for $1 \mathrm{~min}$ at room temperature using a double-cylinder-type homogenizer (Physcotron, Microtec Nition Co., Japan); sonication was then performed for 4 min using a ultrasonic homogenizer (US-300T, Nissei, Japan), to obtain a transparent TOCN dispersion with sodium carboxylate groups (TOCN-COONa). The dispersion was centrifuged at 12000 gravity for 20 min to remove the small partly fibrillated or unfibrillated fraction $(<10 \%)$. The width and average length of the TOCNs were $3 \mathrm{~nm}$ and $1087 \mathrm{~nm}$, respectively [40]. A $1 \mathrm{M} \mathrm{HCl}$ aqueous solution was slowly added to the TOCN-COONa/water dispersion 
to form a TOCN gel with free carboxyl groups (TOCN-COOH). The $\mathrm{pH}$ of the medium was adjusted to $\sim 2$, and stirring was then performed at room temperature for $30 \mathrm{~min}$. The TOCN$\mathrm{COOH}$ gel was collected and washed with water, and solvent exchange to chloroform was achieved through ethanol, using centrifugation. A $1 \mathrm{w} / \mathrm{v} \%$ solution of $\mathrm{PEG-NH_{2 }}$ in chloroform was added to the TOCN-COOH gel, where the molar ratio of PEG- $\mathrm{NH}_{2}$ to the carboxyl groups was adjusted to 1:1. The PEG-TOCN/chloroform dispersion was obtained via the application of sonication for $3 \mathrm{~min}$.

\subsection{Preparation of PEG-TOCN/PLLA composite films}

PEG-TOCN/PLLA composite films were prepared by casting the mixtures of the PLLA solution and the PEG-TOCN dispersion in chloroform (Scheme S1 in Supplementary file). PLLA was dissolved in chloroform with a concentration of $20 \mathrm{mg} \mathrm{mL}^{-1}$. The PLLA solution and PEG-TOCN dispersion were mixed at different ratios, and stirred for 30 min. The mixtures were cast in poly(fluoro acetate) petri dishes and dried at $30^{\circ} \mathrm{C}$, and this was followed by vacuum-drying at room temperature for $24 \mathrm{~h}$.

\subsection{Analyses}

Thermal analysis of the samples was carried out using a Perkin-Elmer differential scanning calorimetry (DSC) 8500 instrument. Samples (2-3 mg) were sealed in aluminum pans. For the non-isothermal crystallization study, the samples were heated to $185^{\circ} \mathrm{C}$, maintained at this temperature for $2 \mathrm{~min}$, and then rapidly cooled to $0^{\circ} \mathrm{C}$. The parameters were 
collected during the second heating run from 0 to $185^{\circ} \mathrm{C}$ at a heating rate of $20^{\circ} \mathrm{C} \mathrm{min}^{-1}$. In the isothermal study, samples were heated to $185^{\circ} \mathrm{C}$, and then maintained at this temperature for 2 min to erase any thermal history. The samples were then quenched to a desired crystallization temperature $\left(85,90,95,100,105,110,115\right.$, and $\left.120^{\circ} \mathrm{C}\right)$, and then held at that temperature until the isothermal crystallization was complete. The degree of crystallinity $\left(X_{\mathrm{c}}\right)$ of the PLLA after isothermal crystallization for 60 min was calculated from the DSC heating curve using the following equation,

where $\Delta H_{\mathrm{cc}}$ and $\Delta H_{\mathrm{m}}$ are the cold crystallization enthalpy and melting enthalpy, respectively, and $\Delta H_{\mathrm{m}}{ }^{\infty}$ is the theoretical melting enthalpy of $100 \%$ crystallized PLLA $\left(93.0 \mathrm{~J} \mathrm{~g}^{-1}\right)$ [51]. Wide-angle X-ray diffraction (WAXD) measurements were carried out using a Rigaku RINT2000 diffractometer with $\mathrm{Cu} \operatorname{K\alpha }$ radiation $(\lambda=1.5418 \AA)$ at $40 \mathrm{kV}$ and $40 \mathrm{~mA}$. The spherulite morphology of the PLLA crystal was observed using a Nikon E600 POL polarized microscope equipped with two hot stages. The sample was initially melted at $185^{\circ} \mathrm{C}$ for 2 min on one of the stages, and was then immediately transferred to another stage that had been preheated to the desired crystallization temperature $\left(85-120^{\circ} \mathrm{C}\right)$. The images were captured using Motic Image Plus 2.2S software. Tensile tests were carried on films with a thickness of $\sim 150 \mu \mathrm{m}$ using a Shimadzu EZ-TEST tensile tester equipped with a $500 \mathrm{~N}$ load cell. Specimens with a length of $30 \mathrm{~mm}$ and a width of $2 \mathrm{~mm}$ were measured at an extension rate 
147

of $20 \mathrm{~mm} \mathrm{~min}^{-1}$ with a $10 \mathrm{~mm}$ span length. At least 5 specimens were measured for each sample. Thermal mechanical analysis (TMA) was carried out using a $0.03 \mathrm{~N}$ load in a nitrogen atmosphere, at temperatures from 30 to $140^{\circ} \mathrm{C}$, with a heating rate of $5^{\circ} \mathrm{C} \mathrm{min}{ }^{-1} \mathrm{using}$ a Shimadzu thermomechanical analyzer (Shimadzu, Japan, TMA-60). The change in specimen length with temperature was recorded, and the linear coefficient of thermal expansion (CTE) was calculated.

\section{Results and discussion}

\subsection{Non-isothermal crystallization behavior}

The addition of PEG(23)-TOCN and PEG(48)-TOCN significantly increased the crystallization rate of PLLA under heating. The cold crystallization peaks of PLLA became sharp, and the cold crystallization temperature $\left(T_{\mathrm{cc}}\right)$ decreased from 134 to 120 and $111^{\circ} \mathrm{C}$ by the addition of $1.0 \%$ PEG(23)-TOCNs and PEG(48)-TOCNs, respectively (Table 1 and Fig. 1).

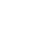

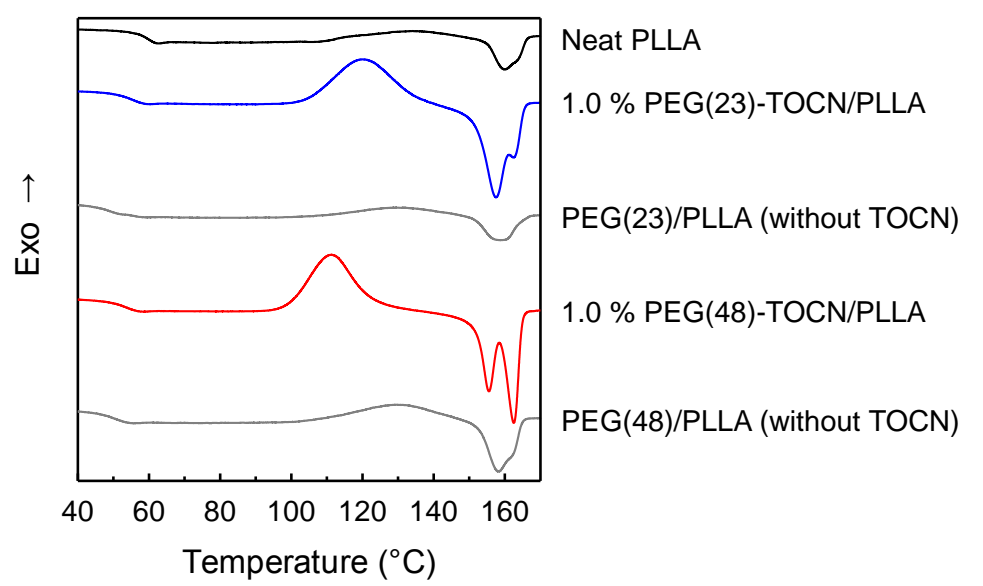

Fig. 1. DSC curves for PLLA, the 1.0\% PEG-TOCN/PLLA composites, and the PEG/PLLA blends in the second heating run (heating rate: $20^{\circ} \mathrm{C}^{-1}$ ). 


\section{Table 1}

170 Thermal properties of PEG-TOCN/PLLA composites and PEG/PLLA blends in the second heating run (heating rate: $20{ }^{\circ} \mathrm{C} \mathrm{min}^{-1}$ ).

\begin{tabular}{lccccccc}
\hline Sample & $\begin{array}{c}\text { Weight content } \\
\text { (wt \%) }\end{array}$ & $T_{\mathrm{g}}$ & $T_{\mathrm{cc}}$ & $\Delta H_{\mathrm{cc}}$ & $T_{\mathrm{m}}$ & $\Delta H_{\mathrm{m}}$ \\
& TOCN & PEG & $\left({ }^{\circ} \mathrm{C}\right)$ & $\left({ }^{\circ} \mathrm{C}\right)$ & $\left(\mathrm{J} \mathrm{g}^{-1}\right)$ & $\left({ }^{\circ} \mathrm{C}\right)$ & $\left(\mathrm{J} \mathrm{g}^{-1}\right)$ \\
\hline Neat PLLA & 0 & 0 & 58.3 & 134.0 & 10.6 & 160.0 & 10.6 \\
$\begin{array}{l}\text { 1.0\% PEG(23)- } \\
\text { TOCN/PLLA composite }\end{array}$ & 1.0 & 1.5 & 50.5 & 120.0 & 39.8 & 157.5 & 39.8 \\
PEG(23)/PLLA blend & 0 & 1.5 & 48.9 & 129.3 & 10.5 & 158.8 & 10.5 \\
$\begin{array}{l}1.0 \% \text { PEG(48)- } \\
\text { TOCN/PLLA composite }\end{array}$ & 1.0 & 3.0 & 51.9 & 111.3 & 40.8 & 155.5 & 40.9 \\
& & & & & & 162.5 & \\
PEG(48)/PLLA blend & 0 & 3.0 & 49.1 & 129.5 & 19.0 & 158.3 & 19.0 \\
\hline
\end{tabular}

In this study, the weight contents were based on the contents of TOCN without PEG

moieties. The cold crystallization enthalpy $\left(\Delta H_{\mathrm{cc}}\right)$ increased with increasing PEG-TOCN

contents. In contrast, no such nucleating effect was observed in the PEG/PLLA blends

(without TOCN) at these weight contents. The $T_{\mathrm{g}}$ of the PLLA matrix decreased with increasing PEG contents. Moreover, the melting peak of pure PEG molecules at $\sim 55^{\circ} \mathrm{C}$ (Fig.

S1 in Supplementary file) was not observed at all in the DSC curves of Fig. 1, which showed that the PEG chains were sufficiently miscible in the PLLA matrix in this system.

PEG chains are typically used as a plasticizing agent for PLLA, and can significantly 
increase the cold crystallization rate of PLLA (by >10 wt \%) [23-25]; the PEG chains enhance the chain mobility of PLLA as the density of PEG chains increases, which leads to a reduction in the energy required for the chain folding process during crystallization [26,27]. In this study, the PEG chains, which were not immobilized on the surface of the TOCNs, did not enhance the cold crystallization at all, probably due to the low PEG density in the matrix. However, when the PEG chains were densely anchored on the TOCN surfaces ( 1.4 chains $\mathrm{nm}^{-2}$ ), the chains significantly enhanced the crystallization rate of the PLLA; the rate increased as the PEG content in the composite films was increased (Table 1). This demonstrated that the sufficiently dispersed PEG-TOCN elements with large surface areas efficiently initiated the nucleation of PLLA. Moreover, because PEG(48)-TOCN/PLLA had a $T_{\mathrm{cc}}\left(111^{\circ} \mathrm{C}\right)$ lower than that of PEG(23)-TOCN/PLLA $\left(120^{\circ} \mathrm{C}\right)$, the PLLA mobility may have been increased by the dense PEG layers on the TOCN surfaces, which resulted in a reduction in the energy required during crystallization. In addition, double melting behavior was observed in the PEG-TOCN/PLLA composites (Fig. 1), which is explainable in terms of melting-recyrstallization-remelting phenomenon.

\subsection{Isothermal crystallization behavior}

The isothermal crystallization behavior of the composites was investigated using DSC.

Neat PLLA and the PEG-TOCN/PLLA composites were melted at $185^{\circ} \mathrm{C}$ for 2 min, and subsequently cooled to different isothermal crystallization temperatures $\left(T_{\mathrm{c}}\right)$. Figure 2 shows the crystallization half-time $\left(t_{1 / 2}\right)$ as a function of the crystallization temperature $T_{\mathrm{c}}$, which 


$$
X_{t}=\frac{\int_{0}^{t}(d H / d t) d t}{\int_{0}^{\infty}(d H / d t) d t} \times 100 \quad(\%)
$$

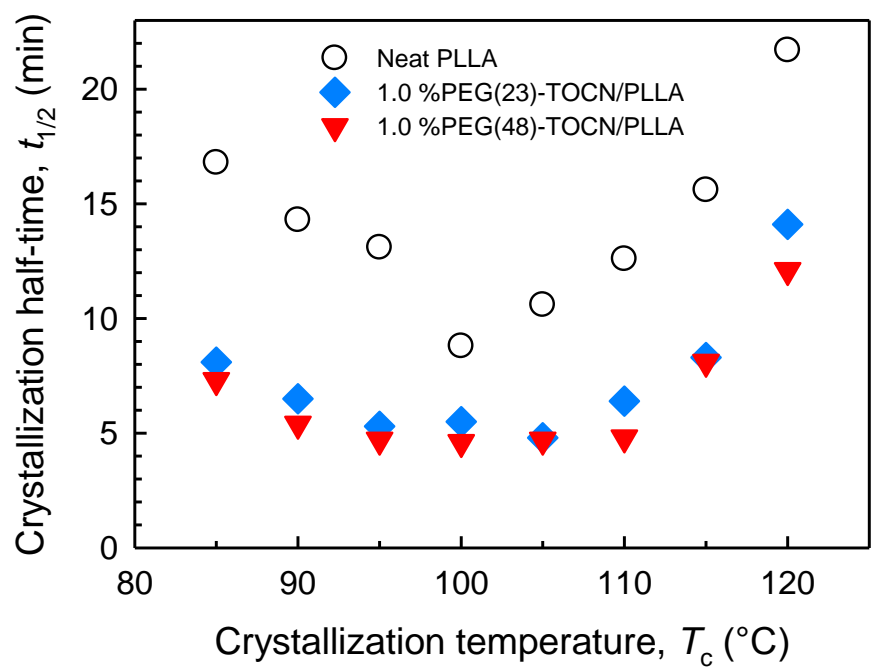

Fig. 2. The crystallization half time $\left(t_{1 / 2}\right)$ of the PLLA film, and the $1.0 \%$ PEG(23)TOCN/PLLA and 1.0\% PEG(48)-TOCN/PLLA composite films.

(Fig. 2). The minimum $t_{1 / 2}$ value for the neat PLLA and the PEG-TOCN/PLLA composites 
$1 \%$ nanocellulose prepared by aqueous counter collision $\left(t_{1 / 2}=3.4 \mathrm{~min}\right.$ at $\left.130{ }^{\circ} \mathrm{C}\right)$ [36]. In contrast, when only PEG molecules without TOCNs were added to the PLLA matrix, the enhancement in isothermal crystallization was not as significant as that achieved using the PEG-TOCNs (Table S1 in Supplementary file). Thus, the isothermal crystallization of PLLA was effectively enhanced by PEG-TOCNs. theory [51-53]. In the Avrami equation, $X_{t}$ is described as,

The crystallization kinetics of the samples were described using the well-known Avrami where $n$ is the Avrami exponent and $k$ is the rate constant of crystallization. In this equation, $n$ to give the following equation, and growth dimensions. For the neat PLLA, $n$ was close to 4, indicating homogeneous

is dependent on the crystal shape and the nucleation process. Equation (3) can be rearranged

The parameter $n$ can be obtained from the slope of plots of $\ln \left[-\ln \left(1-X_{t}\right)\right]$ versus $\ln t$.

Figure 3 shows isothermal crystallization curves for neat PLLA and PEG-TOCN/PLLA composites at 95,105 , and $115^{\circ} \mathrm{C}$ and the corresponding Avrami plots. The isothermal peaks became sharper after the addition of the PEG-TOCNs, which clearly showed that they enhanced the isothermal crystallization of PLLA. The $n$ and $X_{\mathrm{c}}$ values obtained from the isothermal peaks are listed in Table 2. The Avrami exponent $n$ was obtained using a linear fitting of the $X_{\mathrm{t}}$ data in the range of $20-70 \%$. This exponent predicts the nucleation mechanism nucleation with a three-dimensional growth [54]. In contrast, the $n$ values of the PEG- 
PLLA crystals occurred with heterogeneous nucleation in two or three dimensions.
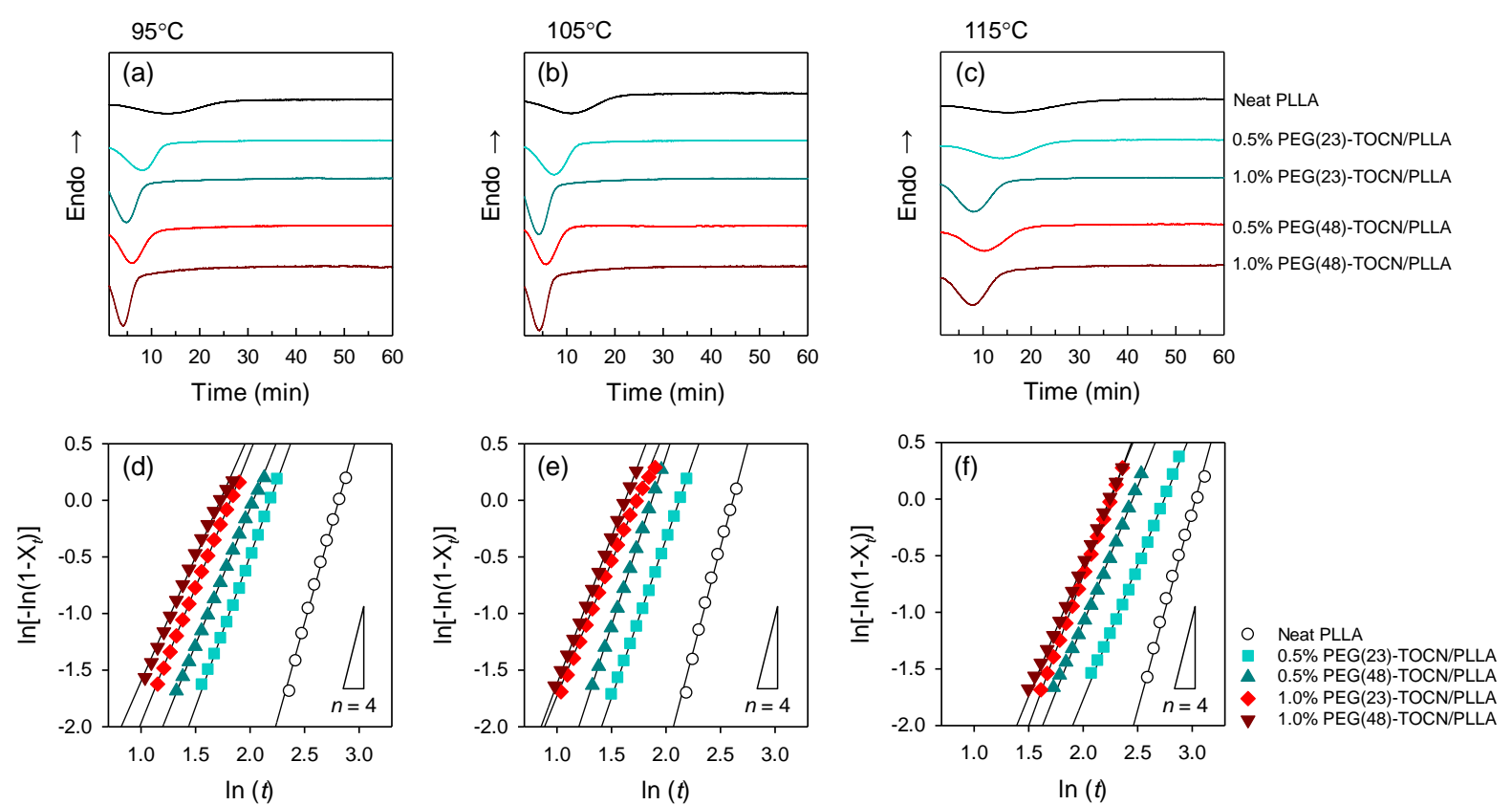

Fig. 3. Isothermal crystallization curves obtained using DSC, and corresponding Avrami plots of $\ln \left[-\ln \left(1-X_{t}\right)\right]$ versus $\ln (t)$ at different temperatures: $(\mathrm{a}, \mathrm{d}) 95^{\circ} \mathrm{C},(\mathrm{b}, \mathrm{e}) 105^{\circ} \mathrm{C}$, and $(\mathrm{c}$, f) $115^{\circ} \mathrm{C}$.

The crystal growth of the neat PLLA and PEG-TOCN/PLLA composites was observed using polarized optical microscopy at different $T_{\mathrm{c}}$ values (Fig. 4). The PEG-TOCN/PLLA composites showed a significantly higher nucleation density than the neat PLLA, because the nucleation was enhanced on the TOCN surfaces. Moreover, no spherulites were observed for the composites; this was different from the behavior observed for the neat PLLA. This was likely because the dense PEG-TOCN networks in the composites prohibited the three- 
films increased with crystallization temperature, and the nucleation rate was lower (Fig. S2 in
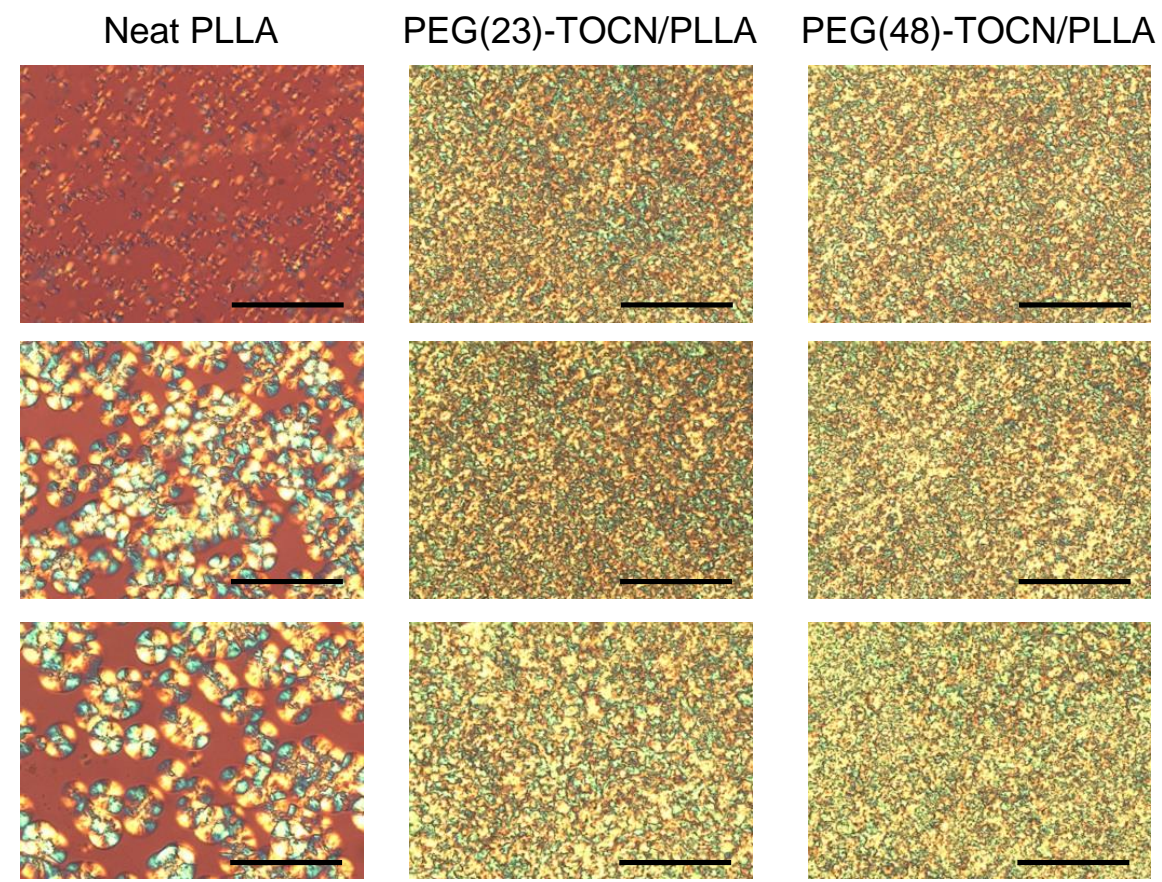

Fig. 4. Optical micrographs of neat PLLA and 1.0\% PEG-TOCN composites observed between crossed polarizers after isothermal crystallization for $10 \mathrm{~min}$ at 95,105 , and $115^{\circ} \mathrm{C}$. The scale bar represents $100 \mu \mathrm{m}$.

$1.0 \mathrm{wt} \%$ TOCN contents. As a result, the TOCN network in the PLLA matrix restricted the dimensionality of the crystal growth of PLLA (which is consistent with the lower $n$ values of the composites, as discussed previously). The size of the PLLA spherulites in the neat PLLA apparently unchanged with temperature in the presence of the TOCN networks. The $X_{\mathrm{c}}$ value 
of PLLA composites containing $25 \mathrm{w} / \mathrm{w} \%$ microcrystalline cellulose $\left(X_{\mathrm{c}}=44.5 \%\right)$ [56]. The

292

293

WAXD patterns showed that the addition of PEG-TOCNs did not change the crystal forms of the neat PLLA at all during isothermal crystallization (Fig. S3 in Supplementary file). Thus, the PEG-TOCNs increased not only the crystallization rate but also the $X_{\mathrm{c}}$ of PLLA, without changing the crystal structure.

\section{Table 2}

Isothermal crystallization kinetics parameters at 95,105 , and $115^{\circ} \mathrm{C}$.

\begin{tabular}{lcccccc}
\hline Sample & \multicolumn{2}{c}{$T_{\mathrm{c}}=95^{\circ} \mathrm{C}$} & \multicolumn{2}{c}{$T_{\mathrm{c}}=105^{\circ} \mathrm{C}$} & \multicolumn{2}{c}{$T_{\mathrm{c}}=115^{\circ} \mathrm{C}$} \\
\cline { 2 - 6 } & $n$ & $X_{\mathrm{c}}(\%)$ & $n$ & $X_{\mathrm{c}}(\%)$ & $n$ & $X_{\mathrm{c}}(\%)$ \\
\hline Neat PLLA & 3.4 & 28.5 & 3.5 & 32.2 & 3.7 & 30.2 \\
$0.5 \%$ PEG(23)-TOCN & 2.7 & 32.4 & 2.8 & 37.0 & 2.4 & 38.0 \\
$1.0 \%$ PEG(23)-TOCN & 2.4 & 33.6 & 2.4 & 39.5 & 2.7 & 41.7 \\
$0.5 \%$ PEG(48)-TOCN & 2.4 & 32.6 & 3.0 & 37.1 & 2.4 & 39.6 \\
$1.0 \%$ PEG(48)-TOCN & 2.2 & 33.7 & 2.6 & 40.1 & 2.3 & 42.1 \\
\hline
\end{tabular}
and $115^{\circ} \mathrm{C}$ for 5 min was evaluated using thermomechanical analysis. The composites exhibited better thermal stability than neat PLLA, due to the increased crystallinity (Fig. 5a).

The thermal expansion of the neat PLLA film increased above the $T_{\mathrm{g}}$ of $\sim 60^{\circ} \mathrm{C}$. In contrast, the thermal expansion values of the composite films were smaller than $4 \%$ in this temperature range. The CTE values of the composites decreased significantly (by approximately one order of magnitude) after the isothermal crystallization, whereas the neat PLLA showed a modest 
PLLA in the composites. The Young's moduli of the samples increased as the degree of
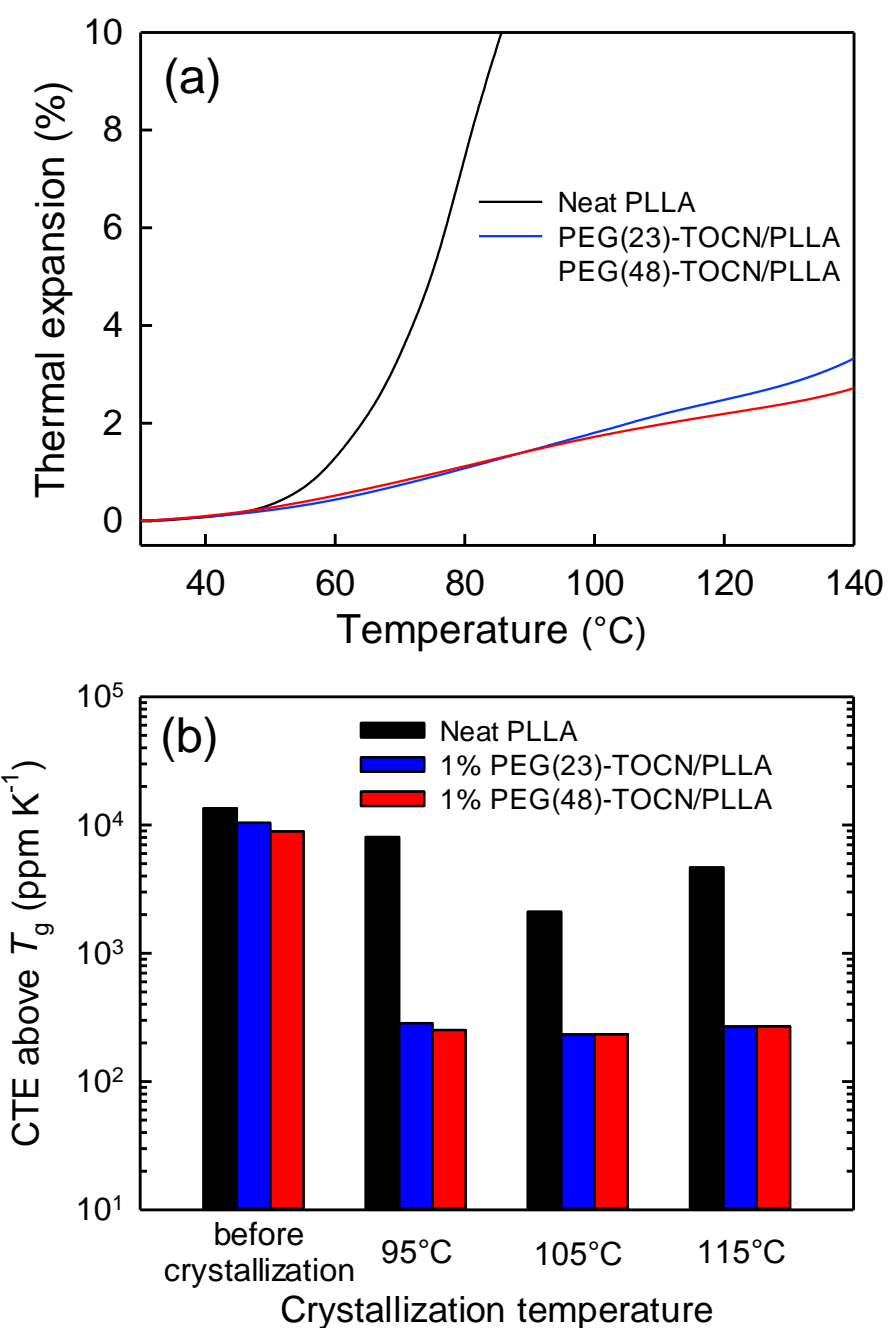

Fig. 5. (a) Thermal expansion behavior and (b) the CTE above $T_{\mathrm{g}}$ of neat PLLA and $1.0 \%$ PEG-TOCN/PLLA composites after isothermal crystallization at 95,105 , and $115^{\circ} \mathrm{C}$ for 5 $\min$. 


\section{Conclusions}

In this study, we demonstrated the potential of PEG-TOCNs as a bio-based nucleating agent for PLLA. The addition of PEG-TOCNs to PLLA matrix significantly increased the crystallization rate of PLLA under heating. The PEG chains densely immobilized on the surface of the TOCNs nanodispersed in PLLA matrix were likely to increase the effective nucleation rate of PLLA. The isothermal crystallization curves obtained using DSC and corresponding Avrami plots of the PEG-TOCN/PLLA composites revealed that the growth of the PLLA crystals occurred with homogeneous nucleation in one or two dimensions in the composites. The dense TOCN networks were likely to form in the composites, resulting that the TOCN network in the PLLA matrix restricted the dimensionality of the crystal growth of crystallinity; the thermal expansion values of the composite films were smaller than $4 \%$. We expect therefore that the surface-modified cellulose nanofibrils are useful as an effective template for the design of nucleating surfaces for biopolymer matrices.

\section{Acknowledgment}

This research was supported by Grants-in-Aid for Scientific Research (Grant number 21228007, 23688020, and 23-3027) from the Japan Society for the Promotion of Science (JSPS), and in part by Core Research for Evolutional Science and Technology (CREST) of Japan Science and Technology Agency (JST). We thank Dr Hironori Marubayashi and Dr Taizo Kabe for discussion. 


\section{Supplementary data} http://dx.doi.org/10.1016/j.polymer.XXXXXXX.

\section{References}

[1] Sinclair RG, J Macromol Sci Pure 1996;A33:585-597.

[2] Auras R, Harte B, Selke S, Macromol Biosci 2004;4:835-864.

[3] Lim LT, Auras R, Rubino M, Prog Polym Sci 2008;33:820-852.

[4] Garlotta D, J Polym Environ 2001;9:63-84.

[5] Ikada Y, Tsuji H, Macromol Rapid Commun 2000;21:117-132.

[6] Kim K, Yu M, Zong XH, Chiu J, Fang DF, Seo YS, Hsiao BS, Chu B, Hadjiargyrou M, Biomaterials 2003;24:4977-4985.

[7] Kolstad JJ, J Appl Polym Sci 1996;62:1079-1091.

[8] Battegazzore D, Bocchini S, Frache A, Express Polym Lett 2011;5:849-858.

[9] Ke TY, Sun XZ, J Appl Polym Sci 2003;89:1203-1210.

[10] Pluta M, Galeski A, Alexandre M, Paul MA, Dubois P, J Appl Polym Sci 2002;86:14971506.

[11] Li XX, Yin JB, Yu ZY, Yan SF, Lu XC, Wang YJ, Cao B, Chen XS, Polym. Compos 2009;30:1338-1344.

[12] Mustapa IR, Shanks RA, Kong I, Asian Trans Basic Appl Sci 2013;3:29-37. 
[13] Basilissi L, Di Silvestro G, Farina H, Ortenzi MA, J Appl Polym Sci 2013;128:30573063.

[14] Zhang Y, Deng BY, Liu QS, Chang G, J Macromol Sci Part B Phys 2013;52:334-343.

[15] Shieh YT, Liu GL, Twu YK, Wang TL, Yang CH, J Polym Sci Part B Polym Phys 2010;48:145-152.

[16] Hu X, An HN, Li ZM, Geng Y, Li LB, Yang CL, Macromolecules 2009;42:3215-3218.

[17] Wu DF, Wu LA, Zhou WD, Zhang M, Yang T, Polym Eng Sci 2010;50:1721-1733.

[18] Xu JZ, Chen T, Yang CL, Li ZM, Mao YM, Zeng BQ, Hsiao BS, Macromolecules 2010;43:5000-5008.

[19] Wang HS, Qiu ZB, Thermochim Acta 2012;527:40-46.

[20] Wang HS, Qiu ZB, Thermochim Acta 2011;526:229-236.

[21] Nakajima H, Takahashi M, Kimura Y, Macromol Mater Eng 2010;295:460-468.

[22] Fundador NGV, Enomoto-Rogers Y, Takemura A, Iwata T, Polym Degrad Stab 2013;98:1064-1071.

[23] Martin O, Averous L, Polymer 2001;42:6209-6219.

[24] Sheth M, Kumar RA, Dave V, Gross RA, McCarthy SP, J Appl Polym Sci 1997;66:1495-1505.

[25] Baiardo M, Frisoni G, Scandola M, Rimelen M, Lips D, Ruffieux K, Wintermantel E, J Appl Polym Sci 2003;90:1731-1738.

[26] Li HB, Huneault MA, Polymer 2007;48:6855-6866.

[27] Lai WC, Liau WB, Lin TT, Polymer 2004;45:3073-3080. 
[28] Nishiyama Y, J Wood Sci 2009;55:241-249.

[29] Sakurada I, Nukushina Y, Ito T, J Polym Sci 1962;57:651-660.

[30] Sturcova A, Davies GR, Eichhorn SJ, Biomacromolecules 2005;6:1055-1061.

[31] Iwamoto S, Kai W, Isogai A, Iwata T, Biomacromolecules 2009;10:2571-2576.

[32] Kose R, Kondo T, J Appl Polym Sci 2013;128:1200-1205.

[33] Pei A, Zhou Q, Berglund LA, Compos Sci Technol 2010;70:815-821.

[34] Suryanegara L, Nakagaito AN, Yano H, Compos Sci Technol 2009;69:1187-1192.

[35] Quillin DT, Caulfield DF, Koutsky JA, J Appl Polym Sci 1993;50:1187-1194.

400

[36] Amash A, Zugenmaier P, Polym Bull 1998;40:251-258.

401

[37] Son SJ, Lee YM, Im SS, J Mater Sci 2000;35:5767-5778.

402

[38] Gray DG, Cellulose 2007;15:297-301.

403

[39] Ten E, Turtle J, Bahr D, Jiang L, Wolcott M, Polymer 2010;51:2652-2660.

404

405

[40] Fujisawa S, Saito T, Kimura S, Iwata T, Isogai A, Biomacromolecules 2013;14:1541-

406

407

408

409

410

[44] Lasseuguette E, Cellulose 2008;15:571-580.

411

[45] Azzam F, Heux L, Putaux JL, Jean B, Biomacromolecules 2010;11:3652-3659.

412

[46] Johnson RK, Zink-Sharp A, Glasser WG, Cellulose 2011;18:1599-1609. 
413 [47] Salajková M, Berglund LA, Zhou Q, J Mater Chem 2012;22:19798-19805.

414 [48] Fujisawa S, Saito T, Isogai A, Cellulose 2012;19:459-466.

415 [49] Fujisawa S, Okita Y, Saito T, Togawa E, Isogai A, Cellulose 2011;18:1191-1199.

416 [50] Nam JY, Ray SS, Okamoto M, Macromolecules 2003;36:7126-7131.

417 [51] Avrami M, J Chem Phys 1939;7:1103-1112.

418 [52] Avrami M, J Chem Phys 1940;8:212-224.

419 [53] Avrami M, J Chem Phys 1941;9:177-184.

420 [54] Miyata T, Masuko T, Polymer 1998;39:5515-5521.

421 [55] Fujisawa S, Ikeuchi T, Takeuchi M, Saito T, Isogai A, Biomacromolecules

422 2012;13:2188-2194.

423

[56] Mathew AP, Oksman K, and Sain M, J Appl Polym Sci 2006;101:300-310.

424

[57] Perego G, Cella GD, Bastioli C, J Appl Polym Sci 1996;59:37-43.

425

[58] Renouf-Glauser AC, Rose J, Farrar DF, Cameron RE, Biomaterials 2005;26:5771-5782.

426 


\section{Cellulose nanofibrils as templates for the design of poly( $\mathrm{L}$ -} 4 lactide)-nucleating surfaces

5

6 Shuji Fujisawa, Jiaqi Zhang, Tsuguyuki Saito, Tadahisa Iwata and Akira Isogai*

7

\section{Graphical Abstract}

\section{Graduate School of Agricultural and Life Sciences, The University of Tokyo, 1-1-1 Yayoi,} Bunkyo-ku, Tokyo 113-8657, Japan

* Corresponding author. Tel: +81 35841 5538; Fax : +81 358415269.

E-mail address: aisogai@mail.ecc.u-tokyo.ac.jp (A. Isogai).

$$
\text { Neat PLLA }
$$

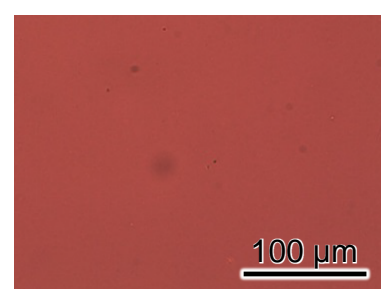

Isothermal crystallization

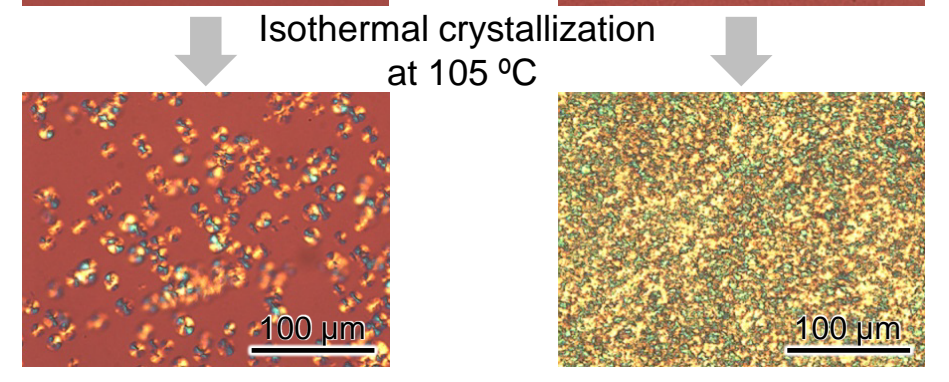

PLLA

$+1 \%$ PEG-modified TOCN

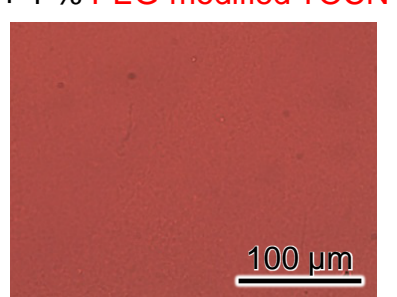

